\title{
Characterization of four Brassica crops for development of diamondback moth Plutella xylostella (L.) (Lepidoptera: Yponomeutidae)
}

\author{
TUFAIL AHMAD ${ }^{1}$ AND M. SHAFIQ ANSARI*
}

Department of Plant Protection, Faculty of Agricultural Sciences, Aligarh Muslim University, ALIGARH (U.P.) INDIA

${ }^{1}$ Department of Plant Protection, Hamelmalo Agricultural College, ERITREA (Email: tufailrm@ gmail.com )

\section{ARITCLE INFO}

Received : 27.12 .2016

Revised : 19.03 .2017

Accepted : 23.03 .2017

\section{KEY WORDS :}

Diamondback moth, Plutella xylostella, Brassica host, Development, Degree days
*Corresponding author: mohdsansari@yahoo.com

\begin{abstract}
Development of Plutella xylostella was studied on cauliflower, cabbage, broccoli and radish in protected field condition under nylon net cage for two consecutive years. Result revealed that $P$. xylostella preferred to lay maximum eggs on cauliflower followed by cabbage, broccoli and radish. Fecundity was more at beginning but declined gradually with advancing of female age. The highest unhatched eggs were recorded on radish and minimum on cauliflower. Larval mortality was least when $P$. xylostella reared on cauliflower and maximum on radish. Mortality survival ratio for immature stages was highest on radish and lowest on cauliflower. The immature stages of $P$. xylostella were over within 27.45 days on cauliflower and 30.62 days on radish. Thermal constants significantly differed among the host plants during both the years of study. Maximum degree-days 66.66 and 125.00 was required for development of $P$. xylostella on cauliflower and minimum 37.03 and 58.82 on radish during both the cropping seasons, respectively. However, P. xylostella required maximum degree days to complete the development of immature stages on broccoli 473.03 and 394.95 degree-days in both cropping years.
\end{abstract}

How to view point the article : Ahmad, Tufail and Ansari, M. Shafiq (2017). Characterization of four Brassica crops for development of diamondback moth Plutella xylostella (L.) (Lepidoptera: Yponomeutidae). Internat. J. Plant Protec., 10(1) : 134-139, DOI : 10.15740/HAS/IJPP/10.1/ 134-139. 